\title{
Selective component degradation of oil palm empty fruit bunches (OPEFB) using high- pressure steam
}

\begin{abstract}
In order to accelerate the bioconversion process of press-shredded empty fruit bunches (EFB), the effect of high-pressure steam pre-treatment (HPST) in degrading the lignocellulosic structure was investigated. HPST was carried out under various sets of temperature/pressure conditions such as 170/0.82, 190/1.32, 210/2.03, and $230{ }^{\circ} \mathrm{C} / 3.00 \mathrm{MPa}$. It was noted that after HPST, the surface texture, color, and mechanical properties of the treated EFB had obviously altered. Scanning electron micrographs of the treated EFB exhibited effective surface erosion that had occurred along the structure. Moreover, the Fourier transform infrared and thermogravimetric analyses showed the removal of silica bodies and hemicellulose ingredients. X-ray diffraction profiles of the treated EFB indicated significant increases in crystallinity. These results reveal that HPST is an effective pretreatment method for altering the physicochemical properties of the EFB and enhancing its biodegradability characteristics for the bioconversion process.
\end{abstract}

Keyword: Empty fruit bunches; High-pressure steam; Selective degradation; Lignocellulosic structure; Pre-treatment 